\title{
An all-ZnO microbolometer for infrared imaging
}

\author{
Yunus Emre Kesim ${ }^{\mathrm{a}, \mathrm{b}, *}$, Enes Battal ${ }^{\mathrm{a}, \mathrm{b}}$, M. Yusuf Tanrikulu ${ }^{\mathrm{c}}$, Ali K. Okyay ${ }^{\mathrm{a}, \mathrm{b}, \mathrm{d}}$ \\ ${ }^{a}$ Department of Electrical and Electronics Engineering, Bilkent University, 06800 Ankara, Turkey \\ ${ }^{\mathrm{b}}$ UNAM-National Nanotechnology Research Center, Bilkent University, 06800 Ankara, Turkey \\ ${ }^{\mathrm{c}}$ Department of Electrical-Electronics Engineering, Adana Science and Technology University, Adana, Turkey \\ ${ }^{\mathrm{d}}$ Institute of Materials Science and Nanotechnology, Bilkent University, 06800 Ankara, Turkey
}

\section{H I G H L I G H T S}

- An all-ZnO microbolometer is proposed.

- ALD grown $\mathrm{ZnO}$ is employed as both the thermistor and the absorber material.

- The all-ZnO microbolometer is computationally analyzed.

- The optical and thermal effects are simultaneously considered.

- Absorptance, time constant and NETD of the all-ZnO microbolometer are extracted.

\section{A R T I C L E I N F O}

\section{Article history:}

Received 19 May 2014

Available online 30 July 2014

\section{Keywords:}

Uncooled infrared imaging

Microbolometers

Zinc oxide

Atomic layer deposition

Transparent conductive oxides

\begin{abstract}
A B S T R A C T
Microbolometers are extensively used for uncooled infrared imaging applications. These imaging units generally employ vanadium oxide or amorphous silicon as the active layer and silicon nitride as the absorber layer. However, using different materials for active and absorber layers increases the fabrication and integration complexity of the pixel structure. In order to reduce fabrication steps and therefore increase the yield and reduce the cost of the imaging arrays, a single layer can be employed both as the absorber and the active material. In this paper, we propose an all-ZnO microbolometer, where atomic layer deposition grown zinc oxide is employed both as the absorber and the active material. Optical constants of $\mathrm{ZnO}$ are measured and fed into finite-difference-time-domain simulations where absorption performances of microbolometers with different gap size and $\mathrm{ZnO}$ film thicknesses are extracted. Using the results of these optical simulations, thermal simulations are conducted using finite-element-method in order to extract the noise equivalent temperature difference (NETD) and thermal time constant values of several bolometer structures with different gap sizes, arm and film thicknesses. It is shown that the maximum performance of $171 \mathrm{mK}$ can be achieved with a body thickness of $1.1 \mu \mathrm{m}$ and arm thickness of $50 \mathrm{~nm}$, while the fastest response with a time constant of $0.32 \mathrm{~ms}$ can be achieved with a $\mathrm{ZnO}$ thickness of $150 \mathrm{~nm}$ both in arms and body.
\end{abstract}

(c) 2014 Elsevier B.V. All rights reserved.

\section{Introduction}

Infrared (IR) imaging market is shifting from defense to civilian sectors with the introduction of new commercial and high volume markets such as automotive, surveillance, thermography, and IR imaging in smartphones (see Fig.1) [1]. This trend created a cost-driven market in favor of uncooled infrared imaging systems. Unlike the cooled counterparts, which operate on photogeneration and collection of electrons and holes, uncooled IR detectors sense the temperature change due to the absorption of the IR

* Corresponding author at: Department of Electrical and Computer Engineering, Carnegie Mellon University, Pittsburgh, PA 15213, USA. radiation. The cooled detectors offer higher performance (higher resolution, higher signal-to-noise ratio, faster response) at a high cost due to the need for cryogenic cooling [2]. On the other hand, uncooled detectors offer cost effective solutions targeting the competitive low-end high-volume user market. Among uncooled detectors such as thermopiles, pyroelectric detectors, and microbolometers, the latter are more popular for infrared imaging purposes [3].

A bolometer pixel consists of an absorber layer, an active detector material (thermistor), and the support arms as given in Fig. 2a [4]. The absorber layer and the thermistor are free-standing for thermal isolation. The absorption of the incident radiation causes an increase in the temperature of the thermistor. This temperature 


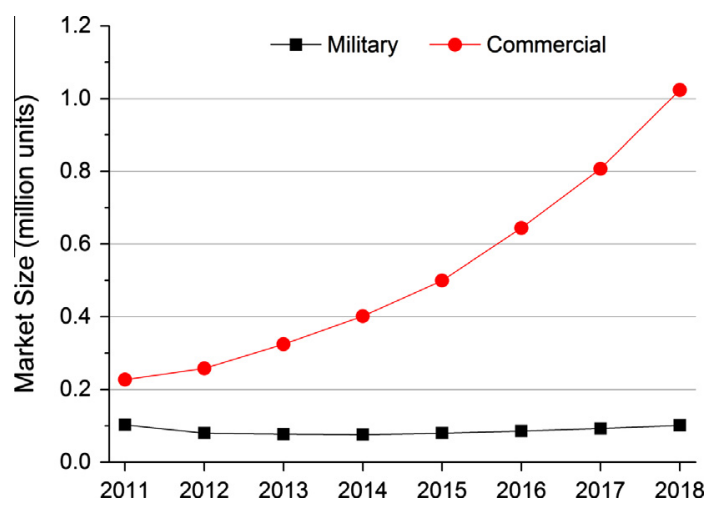

Fig. 1. Global uncooled thermal camera market size forecast in units [1].

increase changes the resistance of the thermistor, and this change is converted to electrical signal by the read-out integrated circuit (ROIC). The percentage of change in the resistance of the thermistor per kelvin is given by the temperature coefficient of resistance (TCR) of the thermistor material.

The key figure of merit indicating the performance of a microbolometer is the noise equivalent temperature difference (NETD) [5] and it is given by

$N E T D=\frac{4 F^{2} V_{n}}{\tau_{0} A_{D} \mathcal{R}_{V}(\Delta P / \Delta T)_{\lambda_{1}-\lambda_{2}}}$

where $V_{n}$ is the total RMS noise voltage, $\tau_{o}$ is the transmission of the optics, $A_{D}$ is the active detector area, $\mathcal{R}_{V}$ is the voltage responsivity of the detector, $(\Delta P / \Delta T)_{\lambda_{1}-\lambda_{2}}$ is the change of power per unit area radiated by a blackbody at temperature $T$, measured within the spectral band of $\lambda_{1}-\lambda_{2}$, and $F$ is a function of distance from the optics to the target. The voltage responsivity, $\mathcal{R}_{V}$ can be expressed as

$\mathcal{R}_{V}=\frac{\Delta V}{P_{0}}=\frac{\eta I_{d} \alpha R_{d}}{G_{t h}}$

where $\eta$ is the absorption coefficient, $I_{d}$ is the detector current, $\alpha$ is the TCR, $R_{d}$ is the detector resistance, $G_{t h}$ is the thermal conductance. Another important parameter affected by the thermal conductance is the time constant of the detector which is given by

$\tau=\frac{C_{t h}}{G_{t h}}$

where $C_{t h}$ is the thermal capacitance. The time constant is a measure of the response time of the microbolometer, and a smaller time constant is desirable for faster sensors. For imaging applications based on $30 \mathrm{~Hz}$ frame rate, a time constant of $10 \mathrm{~ms}$ is tolerable and that for $60 \mathrm{~Hz}$ frame rate should be less than $7 \mathrm{~ms}$ [6].

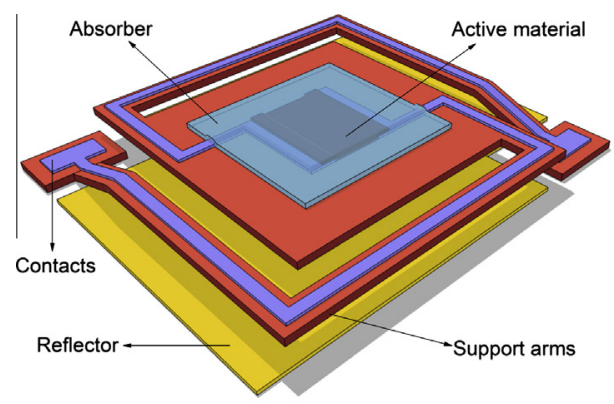

(a)
In order to maximize the responsivity of the microbolometer and reduce the NETD, new materials or sensors architectures that provide higher TCR and absorptivity and lower thermal conductivity are desirable. However, when thermal conductance, $G_{t h}$, is lower, the time constant increases. Due to the trade-off between NETD and time constant, a new figure of merit is defined [7], NETD-thermal time constant product

$F O M=N E T D \cdot \tau$

In terms of thermistor materials, most of the commercially available microbolometers employ vanadium oxide $\left(\mathrm{VO}_{x}\right)$ and amorphous silicon $(\alpha-\mathrm{Si})$ with TCR values between $-2 \% / \mathrm{K}$ and $-3 \% / \mathrm{K}[3,4]$. In addition, alternative active materials reported include but are not limited to thin film metals such as titanium $(0.35 \% / \mathrm{K})[8]$ and platinum $(0.14 \% / \mathrm{K})[9], \mathrm{YBaCuO}(-3.3 \% / \mathrm{K})[10]$ and poly crystalline silicon germanium, poly-SiGe $(\sim 1 \% / C)[11]$. Besides these, there are also reports on the usage of electronic devices such as $\mathrm{Si}$ based diodes $(-2 \mathrm{mV} / \mathrm{K})$ [12], thin film transistors $(6.5 \% / \mathrm{K})[13]$ and SiGe quantum wells $(-5.8 \% / \mathrm{K})$ [14]. Note that the values provided for $\mathrm{Si}$ diodes and thin film transistors are temperature coefficient of voltage and temperature coefficient of channel current, respectively. Also, recently, researchers in our group demonstrated atomic layer deposition (ALD) grown $\mathrm{ZnO}$ as a candidate thermistor material with a TCR value of $-10.4 \% / \mathrm{K}$ [15]. While the most widely used absorber layer is $\mathrm{Si}_{3} \mathrm{~N}_{4}$ [16-19] there are also reports on the use of alternative CMOS compatible dielectrics [20] and thin metals [5,9] as the absorber layer.

The material complexity and process steps of microbolometers could be reduced if the thermistor layer and the absorber layer were consolidated in a single layer. Recently, Yoneoka et al. suggested replacing the thermistor and absorber layers with a thin ALD grown Pt layer [9]. In this work, we propose an all-ZnO microbolometer, where ALD grown ZnO layer is employed as both the thermistor and the absorber as shown in Fig. 2b. We first present optical characterization of $\mathrm{ZnO}$ followed by the computational analysis of a basic microbolometer structure using finite-difference-time-domain (FDTD) method in order to calculate the absorptivity in the long-wave infrared (LWIR) region $(8-12 \mu \mathrm{m})$. In addition, thermal simulations of the microbolometer structure are conducted using finite-element-method, and time constant and NETD values are extracted. The results show that, when a $1.1 \mu \mathrm{m}$ thick $\mathrm{ZnO}$ layer with a gap size of $0.8 \mu \mathrm{m}$ is used, the absorptivity can be as high as $95.6 \%$ yielding an NETD value of $171 \mathrm{mK}$ and a time constant of $6.6 \mathrm{~ms}$. Such a time constant is suitable for imaging applications at $60 \mathrm{~Hz}$ frame rate. Such a detector could be used for low-end applications such as thermography and pedestrian security in automotive. On the other hand, when the $\mathrm{ZnO}$ film thickness is $150 \mathrm{~nm}$ with a gap of $2.1 \mu \mathrm{m}$, the time constant decreases to $0.32 \mathrm{~ms}$ while absorptivity reduces to $50.6 \%$ and NETD increases up to $940 \mathrm{mK}$. Such a high speed

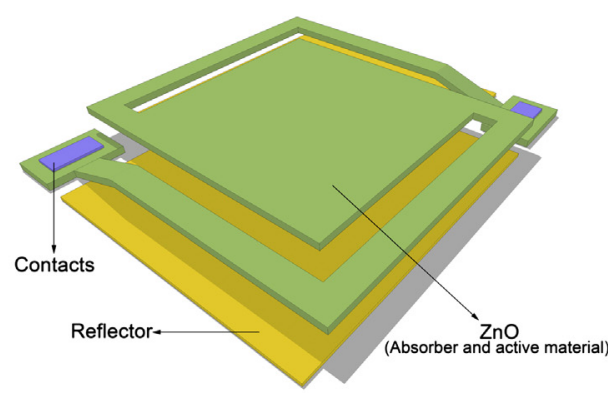

(b)

Fig. 2. (a) Schematic of a conventional microbolometer and (b) single layer all-ZnO microbolometer structure. 
detector could be used for infrared missile seeker applications where a very low time constant is required but a high NETD is tolerable since the object (a hot nozzle) is much hotter than the scene.

\section{ZnO optical properties}

ALD growth of $\mathrm{ZnO}$ is carried out at $120^{\circ} \mathrm{C}$ using a Cambridge Savannah 100 Thermal ALD system using diethylzinc (DEZ) and milli-Q water $\left(\mathrm{H}_{2} \mathrm{O}\right)$ as precursors on n-type (100) Si wafers. Optical characterization of as-grown films is conducted using commercial spectroscopic ellipsometer IR-Vase from J.A. Woollam. The dielectric permittivity of $\mathrm{ZnO}$ is modelled using a Drude oscillator combined with a Lorentz oscillator. Dielectric constants of ALD grown $\mathrm{ZnO}$ is given in Fig. $3 \mathrm{a}$ and refractive indices in the LWIR band are given in Fig. 3b.

\section{Optical simulations}

In order to extract the absorption properties and optimize the proposed all-ZnO single layer microbolometer, electromagnetic simulations are conducted using finite-difference-time-domain (FDTD) technique on a commercial software (FDTD Simulations by Lumerical Inc.). For simplicity, a 2D simulation setup is chosen in which the legs and anchors features of a standard bolometer are neglected as can be seen in Fig. 4a. On the $x$-axis, periodic boundary conditions are assumed. On the $y$-axis, boundary condition at the bottom is chosen as a perfect reflector, to represent the metallic reflector beneath the gap. Metal boundary conditions are perfectly reflecting and do not allow electromagnetic energy to escape the simulation area. On the top, a perfectly matched layer (PML) is assumed. The structure is illuminated with a normally incident plane wave where the wavelength range of the light is 3-15 $\mu \mathrm{m}$. A field monitor is placed behind the plane wave source in order to calculate the absorption in the microbolometer structure. Since all energy incident on the bottom boundary is reflected back, total absorption can be calculated using $P_{a b s}=\left(1-P_{\text {ref }}\right)$ where $P_{\text {ref }}$ is the ratio of the power transmitted through the field monitor to the power radiated by the plane wave source. Therefore, $P_{a b s}$ gives the ratio of absorbed energy to incident energy. The $\mathrm{ZnO}$ film is modeled using the experimental optical constants found in the previous section.

A parameter sweep is conducted to find the optimum structure for which the average absorption in the $8-12 \mu \mathrm{m}$ band is maximized. The thickness of the $\mathrm{ZnO}$ film $(t)$ is varied from $50 \mathrm{~nm}$ to $2 \mu \mathrm{m}$ and the gap height $(\mathrm{g})$ is varied from $100 \mathrm{~nm}$ to $4 \mu \mathrm{m}$. Average absorption in the LWIR band $(8-12 \mu \mathrm{m})$ is calculated (Fig. $4 \mathrm{~b}$ ) by equally weighing absorption at all wavelengths in the $8-12 \mu \mathrm{m}$ band. In general, as t increases, the average absorption increases as

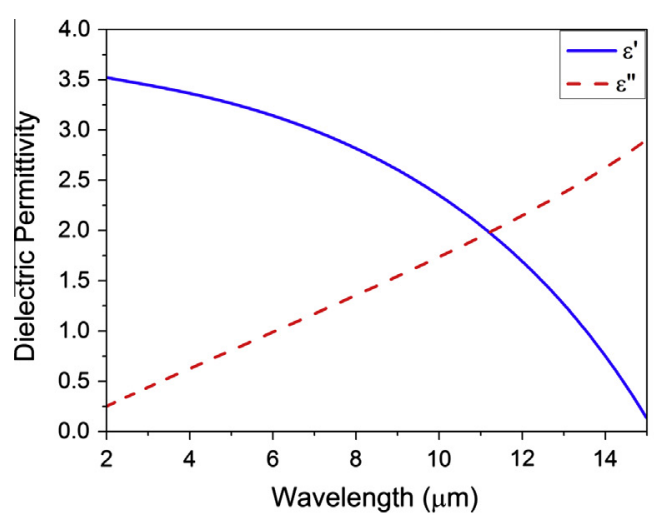

(a)

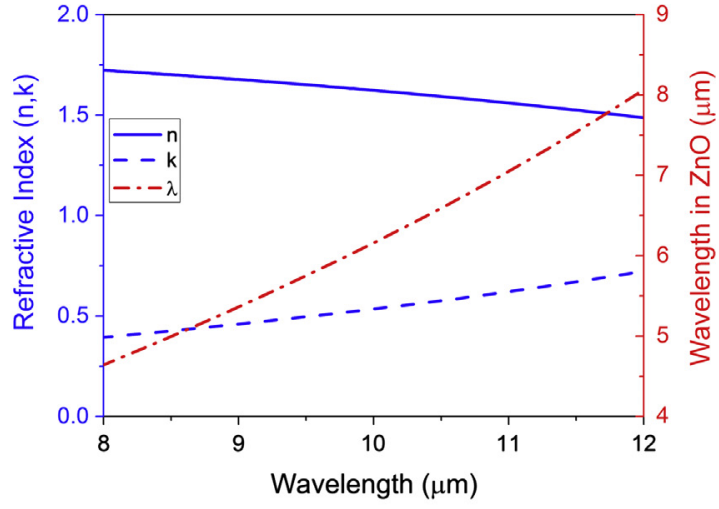

(b)

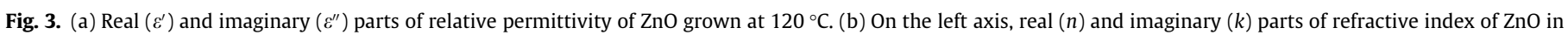
LWIR region. On the right axis, wavelength of incident light in $\mathrm{ZnO}\left(\lambda=\lambda_{o} / n\right)$.

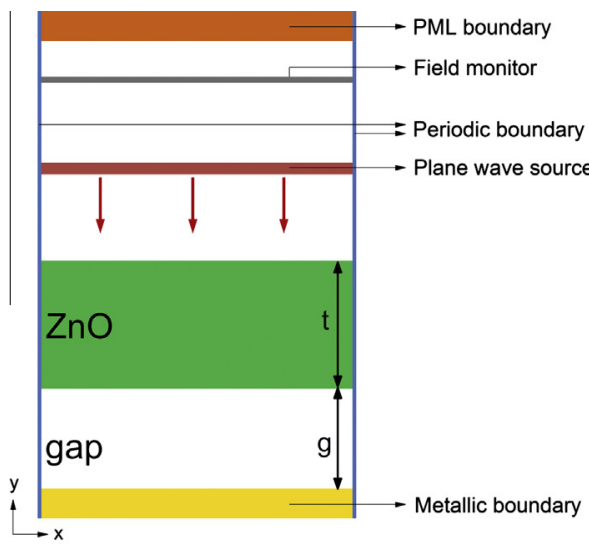

(a)

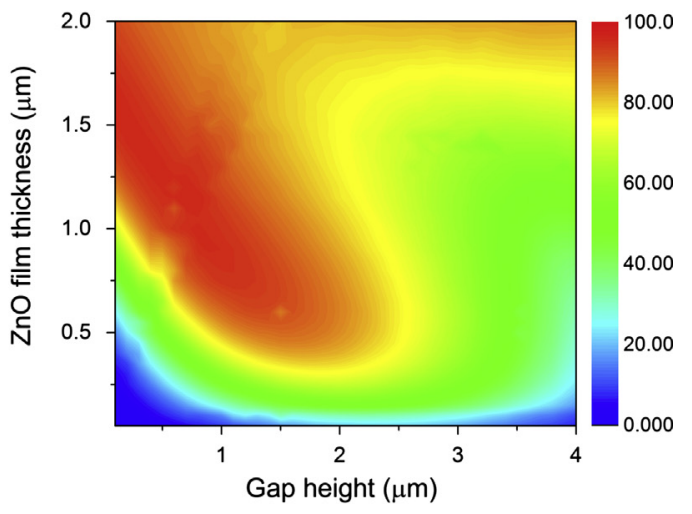

(b)

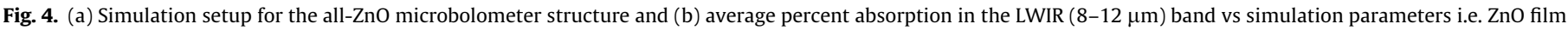
thickness and gap height. 
expected. Average absorption is maximized when $\mathrm{t}$ is between 1.25 and $2 \mu \mathrm{m}$. This is due to the Fabry-Perrot resonance inside the $\mathrm{ZnO}$ film. The resonance condition for the Fabry-Perrot cavity is fulfilled when the cavity length is one fourth of the wavelength of the incident light. When the incident light is in the LWIR band $\left(8 \mu \mathrm{m}<\lambda_{o}<12 \mu \mathrm{m}\right)$, its wavelength inside the $\mathrm{ZnO}$ film is in the 4.5-8 $\mu \mathrm{m}$ range since $\lambda=\lambda_{o} / n$ where $\mathrm{n}$ is the refractive index of $\mathrm{ZnO}$ at the corresponding wavelength (Fig. 3b). Therefore when the film thickness is in the $1.25-2 \mu \mathrm{m}$ range, the resonant wavelength is between 8 and $12 \mu \mathrm{m}$ and this leads to an efficient absorption.

Besides the film itself, the resonant cavity can be formed by the gap beneath. Here, the medium is vacuum and therefore the resonance occurs when the gap height is between 2 and $3 \mu \mathrm{m}\left(\lambda_{o} / 4\right)$. Adjusting the gap height between 2 and $3 \mu \mathrm{m}$, more than $40 \%$ absorption is achieved even with $\mathrm{ZnO}$ films as thin as $100 \mathrm{~nm}$. In Fig. 4, note that, absorption is almost zero for very thin
$(<100 \mathrm{~nm})$ film absorbing layers if the gap height is below $2 \mu \mathrm{m}$. Finally, the results show that maximum absorption (95.6\%) occurs when $t=1.1 \mu \mathrm{m}$ and $g=0.8 \mu \mathrm{m}$.

\section{Thermal simulations}

In order to evaluate the NETD of the all-ZnO microbolometer, it is necessary to know the thermal conductance of the detector besides the parameters given in previous sections. Thermal simulations are conducted in order to estimate the thermal conductance of the detector using the Coventorware simulation tool. For the simulations, the density of $\mathrm{ZnO}$ is taken as $5.6 \mathrm{~g} / \mathrm{cm}^{3}$ [21], specific heat as $40.25 \mathrm{~J} / \mathrm{mol} \mathrm{K}$ [22] and thermal conductivity is used as $90 \mathrm{~W} / \mathrm{m} \mathrm{K}$ [23]. Also, the structural parameters of the simulated pixels are as follows: pixel pitch is $35 \mu \mathrm{m} \times 35 \mu \mathrm{m}$, arm width is $2 \mu \mathrm{m}$ and the fill factor is $50.5 \%$. Several simulations are performed

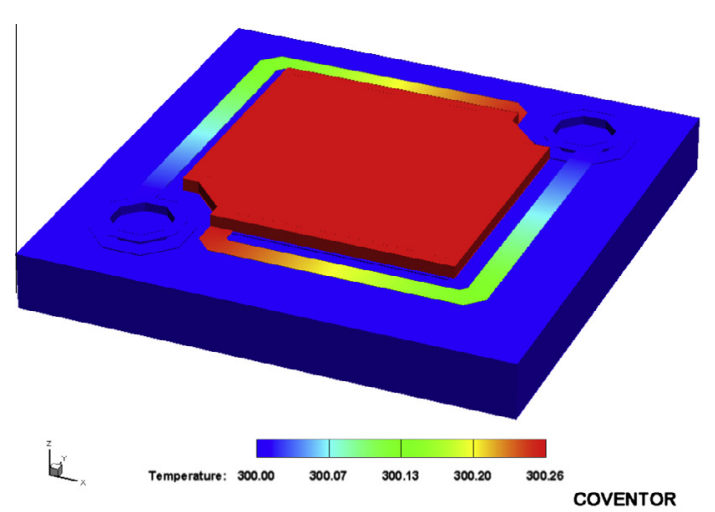

(a)

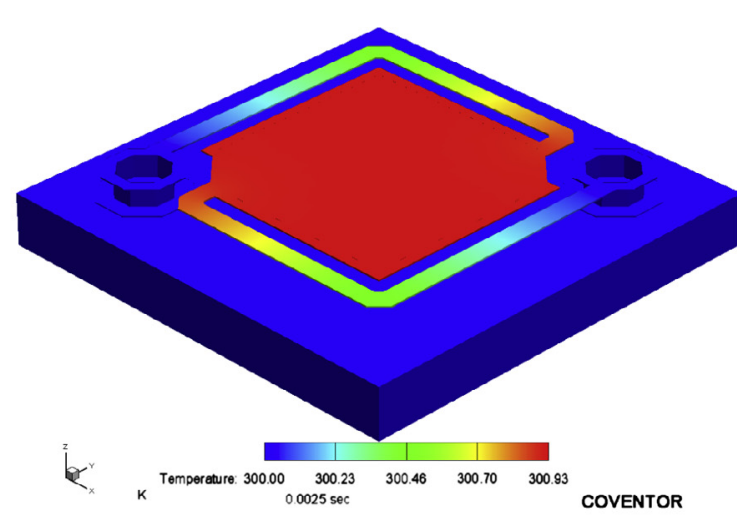

(b)

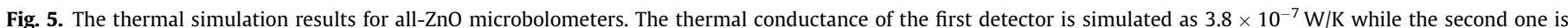
simulated as $1.1 \times 10^{-6} \mathrm{~W} / \mathrm{K}$.

\section{Table 1}

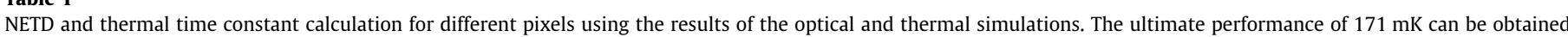

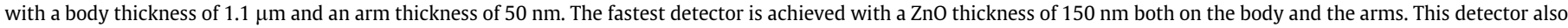
achieves a very low FOM (NETD-thermal time constant product).

\begin{tabular}{|c|c|c|c|c|c|}
\hline Arm thickness $(\mu \mathrm{m})$ & Body thickness $(\mu \mathrm{m})$ & Gap thickness $(\mu \mathrm{m})$ & NETD $(\mathrm{mK})$ & Time constant (ms) & FOM (mK ms) \\
\hline 1.1 & 1.1 & 0.8 & 3575 & 0.33 & 1180 \\
\hline 0.05 & 1.1 & 0.8 & 171 & 6.6 & 1129 \\
\hline 0.15 & 0.15 & 2.1 & 940 & 0.32 & 301 \\
\hline 0.05 & 0.4 & 1.7 & 198 & 2.5 & 495 \\
\hline 0.05 & 0.25 & 2 & 239 & 1.7 & 406 \\
\hline 0.05 & 0.15 & 2.1 & 325 & 0.92 & 299 \\
\hline
\end{tabular}

Table 2

The detector parameters used for the NETD calculation.

\begin{tabular}{|c|c|}
\hline Parameter & Value \\
\hline Pixel area & $35 \mu \mathrm{m} \times 35 \mu \mathrm{m}$ \\
\hline Resistance & $135 \mathrm{k} \Omega$ \\
\hline Active det. area/fill factor & $620 \mu \mathrm{m}^{2} / 50.5 \%$ \\
\hline TCR & $-10.4 \% / \mathrm{K}$ \\
\hline Thermal conductance & $3.8 \times 10^{-7} \mathrm{~W} / \mathrm{K}$ \\
\hline DC responsivity & $5.2 \times 10^{5} \mathrm{~V} / \mathrm{W}$ (@ $2 \mathrm{~V}$ voltage bias including a reference detector in a potential ROIC) \\
\hline Absorptance (absorption efficiency) & $95.6 \%$ \\
\hline FPA size & $384 \times 288$ \\
\hline Integration time@30fps & $100 \mu \mathrm{s}$ \\
\hline Electrical bandwidth & $5 \mathrm{kHz}$ \\
\hline Detector noise & $27 \mu \mathrm{V}_{\mathrm{rms}}$ including the effect of a reference detector in a potential ROIC \\
\hline NETD (f/1 lens, 30 fps frame rate) & $171 \mathrm{mK}$ \\
\hline
\end{tabular}


to understand the effect of the $\mathrm{ZnO}$ thickness on the thermal conductance. Fig. 5a gives the thermal simulation result for the $\mathrm{ZnO}$ thickness of $1.1 \mu \mathrm{m}$ on the body and $50 \mathrm{~nm}$ on the arms while Fig. 5b shows the result for $\mathrm{ZnO}$ thickness of $150 \mathrm{~nm}$ for both body and the arms. In the first simulation $100 \mathrm{nW}$ heat is generated on the pixel while in the second one $1000 \mathrm{nW}$ heat is generated. The thermal conductance of the first detector is simulated as $3.8 \times 10^{-7} \mathrm{~W} / \mathrm{K}$ while the second one is simulated as $1.1 \times 10^{-6} \mathrm{~W} / \mathrm{K}$. Table 1 shows the NETD calculation and simulated thermal time constant for different pixels using the results of the optical and thermal simulations. The fastest detector is achieved with a ZnO thickness of $150 \mathrm{~nm}$ both on the body and the arms. As can be seen from the table the ultimate performance of $171 \mathrm{mK}$ can be obtained with a body thickness of $1.1 \mu \mathrm{m}$ and an arm thickness of $50 \mathrm{~nm}$. Also, this pixel structure is the one that achieves the highest absorption rate, 95.6\%. Using the TCR and thermal conductance values given above $\left(10.4 \%\right.$ and $3.8 \times 10^{-7}$, respectively) and assuming a voltage drop of $2 \mathrm{~V}$ over the pixel (a reference detector with identical resistance value is assumed to exist in the system in order to cancel bias heating effect), responsivity can be calculated as $5.2 \times 10^{5} \mathrm{~V} / \mathrm{W}$ (the resistance of the pixel is $135 \mathrm{k} \Omega$ [15]). Also, noise spectral density of $\mathrm{ZnO}$ is given in [15] and an RMS voltage noise of $27 \mu \mathrm{V}_{\text {rms }}$ is assumed accordingly. The transmission of optics $\left(\tau_{o}\right)$ is assumed as 0.93 [24]. A list of parameters including some readout related variables assumed for the NETD calculation is given in Table 2 .

\section{Conclusion}

In conclusion, we have introduced all-ZnO microbolometer and present two distinct pixel designs: The detector design with the highest absorption offers an NETD value of $171 \mathrm{mK}$ with a thermal time constant of $6.6 \mathrm{~ms}$, and FOM (NETD-time constant product) of $1129 \mathrm{mK}$ ms. Although the thermal time constant is compatible with $60 \mathrm{~Hz}$ frame rate imaging, this detector is outperformed by the highest performance microbolometers available in today's technology that achieve $<50 \mathrm{mK}$ NETD. Nevertheless, such a microbolometer can be used in low-end applications such as thermography and automotive.

Our fastest detector design shows $0.32 \mathrm{~ms}$ thermal time constant with an NETD of $940 \mathrm{mK}$ and FOM of $301 \mathrm{mK}$ ms. This detector is suitable for applications where the speed is of the primary importance such as missile tracking. This application does not require a very low NETD value since the object to be tracked (a missile nozzle in this case) is a lot hotter than the scene.

Consolidating absorber and thermistor layers within a single $\mathrm{ZnO}$ layer, the main advantage of the all-ZnO microbolometer is the reduced material complexity and number of fabrication steps. This advantage leads to higher yield and taking into account the simple growth technology offered by ALD, all-ZnO microbolometer appears as a low cost alternative.

\section{Conflict of interest}

The authors certify that there is no conflict of interest with any financial organization regarding the material discussed.

\section{Acknowledgements}

This work was supported by the Scientific and Technological Research Council of Turkey (TUBITAK), Grant Numbers 112M004, 112E052, 113M815 and 113M912. Y.E.K. and E.B. acknowledge
TUBITAK-BIDEB for national M.Sc. fellowship. The authors certify that there is no conflict of interest with any financial organization regarding the material discussed.

\section{References}

[1] Yole Development, Uncooled Infrared İmaging Technology \& Market Trends Report 2013, Market \& Technology Report.

[2] A. Rogalski, History of infrared detectors, Opto-Electron Rev 20 (3) (2012) 279308.

[3] F. Niklaus, C. Vieider, H. Jakobsen, MEMS-based uncooled infrared bolometer arrays: a review, in: Proc. SPIE 6836, MEMS/MOEMS Technologies and Applications III, 68360D (January 04, 2008).

[4] M.Y. Tanrıkulu, An Uncooled Infrared Microbolometer Detector Array Using Surface Micromachined MEMS Technology, Dissertation for the Degree of Doctor of Philosophy, Middle East Technical University, Department of Electrical and Electronics Engineering, 2007

[5] P.W. Kruse, D.D. Skatrud, Uncooled infrared imaging arrays and systems, Semiconductor and Semimetals, vol. 47, Academic Press, 1997.

[6] J.L. Tissot, C. Trouilleau, B. Fieque, A. Crastes, O. Legras, Uncooled microbolometer detector: recent developments at Ulis, in: Proc. SPIE 5957, Infrared Photoelectronics, 59570M (September 29, 2005).

[7] M. Kohin, N. Butler, Performance limits of uncooled VOx microbolometer focal plane arrays, in: Proc. SPIE 5406, Infrared Technology and Applications XXX, 447 (August 30, 2004).

[8] A. Tanaka, S. Matsumoto, N. Tsukamoto, S. Itoh, K. Chiba, T. Endoh, A. Nakazato, K. Okuyama, Y. Kumazawa, M. Hijikawa, H. Gotoh, T. Tanaka, N. Teranishi, Infrared focal plane array incorporating silicon IC process compatible bolometer, IEEE Trans. Electron Dev, 43 (1996) 11.

[9] S. Yoneoka, M. Liger, G. Yama, R. Schuster, F. Purkl, J. Provine, F.B. Prinz, R.T. Howe, T.W. Kenny, ALD-Metal Uncooled Bolometer, in: Proceedings of IEEE MEMS 2011 (Cancun, Mexico, January 23-27, 2011), pp. 676-679.

[10] A. Jahanzeb, C.M. Travers, Z. Celik-Butler, D.P. Butler, S.G. Tan, A semiconductor YBaCuO microbolometer for room temperature IR imaging, IEEE Trans. Electron Dev. 44 (10) (1997) 1795-1801.

[11] V.N. Leonov, N.A. Perova, P. De Moor, B. Du Bois, C. Goessenss, B. Grietens, A Verbist, C.A. Van Hoof, J.P. Vermeiren, Micromachined poly-SiGe bolometer arrays for infrared imaging and spectroscopy, in: Proc. SPIE 4945, MEMS/ MOEMS: Advances in Photonic Communications, Sensing, Metrology, Packaging and Assembly, 54 (March 24, 2003).

[12] S. Eminoglu, D.S. Tezcan, M.Y. Tanrikulu, T. Akin, Low-cost uncooled infrared detectors in CMOS process, Sens. Actuat. A: Phys. 109 (1-2) (2003) 102-113.

[13] L. Dong, R.F. Yue, L.T. Liu, A high performance single-chip uncooled a-Si TFT infrared sensor, in: TRANSDUCERS, Solid-State Sensors, Actuators and Microsystems, 12th International Conference on, vol. 1, pp. 312-315 (June 8-12, 2003)

[14] F.B. Atar, A. Yesilyurt, M.C. Onbasli, O. Hanoglu, A.K. Okyay, Ge/SiGe quantum well p-i-n structures for uncooled infrared bolometers, IEEE Electron Dev. Lett. 32 (11) (2011) 1567-1569.

[15] E. Battal, S. Bolat, M.Y. Tanrikulu, A.K. Okyay, T. Akin, Atomic layer deposited zinc-oxide as tunable uncooled infrared microbolometer material, Phys. Status Solidi A (2014), http://dx.doi.org/10.1002/pssa.20143119.

[16] S.Z. Lulec, S.E. Kucuk, E. Battal, A.K. Okyay, M.Y. Tanrikulu, T. Akin, An analysis for the broad-band absorption enhancement using plasmonic structures on uncooled infrared detector pixels, in: Proc. SPIE 8353, Infrared Technology and Applications XXXVIII, 83531D (May 31, 2012).

[17] O. Erturk, E. Battal, S.E. Kucuk, A.K. Okyay, T. Akin, A plasmonically enhanced pixel structure for uncooled microbolometer detectors, in: Proc. SPIE 8704, Infrared Technology and Applications XXXIX, 87041E (June 11, 2013).

[18] B. Kebapci, O. Dervisoglu, E. Battal, A.K. Okyay, T. Akin, Broadband absorption enhancement in an uncooled microbolometer infrared detector, in: Proc. SPIE 9070, SPIE Infrared Technology and Applications XL (May 6, 2014).

[19] W.A. Radford, R. Wyles, J. Wyles, J.B. Varesi, M. Ray, D.F. Murphy, A. Kennedy, A. Finch, E.A. Moody, F. Cheung, R. Coda, S.T. Baur, Microbolometer uncooled infrared camera with 20-mK NETD, in: Proc. SPIE 3436, Infrared Technology and Applications XXIV, 636 (October 26, 1998.

[20] D.S. Tezcan, S. Eminoglu, T. Akin, A low-cost uncooled infrared microbolometer detector in standard CMOS technology, IEEE Trans. Electron Dev. 50 (2) (2003) 494-502.

[21] R.C. Weast, M.J. Astle, W.H. Beyer, CRC Handbook of Chemistry and Physics, vol. 69, CRC Press Boca Raton, FL, 1988.

[22] International Zinc Association, Zinc Oxide Properties, <http://www.zinc.org/ info/zinc_oxide_properties> (accessed 14.03.14).

[23] J. Alvarez-Quintana, E. Martinez, E. Perez-Tijerina, S. Perez-Garcia, J. Rodriguez-Viejo, Temperature dependent thermal conductivity of polycrystalline ZnO films, J. Appl. Phys. 107 (6) (2010) 063713.

[24] Janos Technology, TYTO lenses datasheet, <http://www.janostech.com/ products-services/thermal-imaging-lenses/tyto-lenses.html> (accessed 14.03.14). 